\title{
The Relative Contribution of Sports Recreational Preferences in Predicting Social Adjustment among the International Students at Mansoura University *Dr/ Mohamed Ibrahim Al-Zahabi **Dr/ Hossam Abdul Aziz Jouda
} Abstract:

The research aims at determining the relative contribution of sports recreational preferences in the prediction of social adjustment among the international students in Mansoura University. The researchers used the descriptive approach (correlational relations). The sample included 343 students who were chosen by stratified method of international students. The researchers prepared Sports Recreational Preferences Scale and used the Social Adjustment Scale (prepared by Baker R and Siryk B 1989) as data collection tools.

The most important results showed that running, walking, biking and pentagon football were the favorite sportive activities for the international students in their free time. In addition, male Arab students practicing recreational activities enjoyed a higher degree of social adjustment than females and non-Arab students. What means that preferred sports recreational activities contributes highly in the level of social adjustment of foreign students.

Keywords: sports recreational preferences, social adjustment, international students.

\section{Introduction:}

Education is one of the main pillars of development in developed countries and the cornerstone of policy-making, planning and management of inclusive development that ensures the advancement of society and excellence in

competition at different levels. The approach to upgrading the education and innovation system is one of the most important goals that nations seek to it to develop scientific and practical levels and to achieve the optimal investment

\footnotetext{
"Assistant Professor, Department of Sports Recreation - Faculty of Physical

Education - Mansoura University - Arab Republic of Egypt.

"Assistant Professor, Department of Sports Recreation - Faculty of Physical Education - Mansoura University - Arab Republic of Egypt.
} 
of available resources to compete in the global markets. Education is a prerequisite for the pursuit of growth and development, where the presence of foreign students depends on the attractions and diversity of education.

Therefore, the Egyptian universities, including Mansoura University, have developed many distinguished academic programs in various disciplines to attract students from all Arab, African and European countries. The number of students coming to Mansoura University reached (3665) in the academic year $2016 / 2017$. They study in both bachelor and postgraduate stages.

The environmental, economic and social aspects of foreign students vary due to different habits, characteristics, language and perhaps religion, which sometimes contributes to different forms of psychological, academic, economic and social problems that affect social adjustment and lack of communication with colleagues.

Al-Qudah

showed that social adjustment makes the foreign students control their passions, carry out their responsibilities, understand their goals, move away from self-centered, accept others, allow themselves to match with colleagues what leads to a great degree of personal and social maturity (8: 101).

\begin{tabular}{lrr}
\multicolumn{2}{c}{ International } & students \\
should enjoy & free
\end{tabular} psychological and social life partly away of constant tensions and conflicts, which makes them, live in peace and perseverance, far from the paradox in their behaviors.

Mustafa and Al-Sherifin (2014) saw that the students' attempts to integrate into the new social networks is not easy, especially if some individuals reject them. They are also required to search for their psychological identity in the new university environment that they will live with for many more coming years (24: 141).

Therefore, the administration of Mansoura University sought to facilitate the international students staying and to provide all the conditions that help them to achieve and to have good accommodation by opening channels of 
communication with officials and allowing them to establish their own clubs. A club was established for international students through which students practice scientific, cultural, social, technical and sports activities, with the aim of exchanging experiences among students and linking different cultures.

The management of the university's expatriate club was concerned with sports recreational activities through the development of an annual plan, which includes all activities that are preferred to practice in order to achieve effective communication between students from different communities in the university and create an atmosphere of familiarity and affection among them.

The practice of sports recreational activities is an important factor in shaping the different capacities of international students, by providing practical opportunities for selfexpression, satisfying tendencies and desires and developing preparations in a manner that satisfies the society, what affecting the integrity and growth of personality in a balanced manner

\section{The Problem:}

The number of students coming to the Arab Republic of Egypt is increasing significantly, leading to increased awareness among many researchers on a wide range of scientific topics, containing academic issues and social adjustment. Therefore, higher education institutions must develop support services to assist foreign students in their needs that vary from adjusting to academic requirements, to dealing with cultural factors in new societal environments.

International students may face many problems, including changes in identity, academic barriers and pressures from moving to the new environment as they are in adolescence. International students can identify some of the most common problems, mostly because they are unfamiliar with the new culture, language barriers, cultural trauma, the sense of power to acquire cultural skills, biases, nostalgia to home and loneliness. 
Al-Dabboubi and Badawi (2014) note that international students face many psychological, educational, environmental, cultural and social pressures that causes weak sense of responsibility, lack of harmony with others, and thus the difficulty of psychological and social adjustment (5:2).

Therefore, the researchers conducted a pilot study by a semi-formal interview form with (25) foreign students as 20 male students and (5) female students from (6) different countries (Syria, Palestine, Iraq, Sudan, Jordan, Yemen, Nigeria and Malaysia). ). In order to identify their response to some statements related to the subject of the research about preferred recreational activities and the reasons of registration for studying in Mansoura University in the Arab Republic of Egypt (Appendix B).

What showed students' awareness of investing free time, going to their club and make use of the available possibilities at Mansoura University. They preferred sports activities than other activities. They had the desire to study in the Arab Republic of Egypt and gain the adequate knowledge about the nature of the Egyptian society in addition to how to deal with colleagues in university environment in a high-class manner.

Because of the importance of practicing sports recreational activities for international students and contributing to social adjustment, Al-Sagheer (2001) recommended with the importance of encouraging international students to participate in the various extracurricular activities offered by the university and to monitor prizes for those who participate on them regularly, thus strengthening the relationship between foreign students and their peers (9).

Al-Zoghbi (2003) (11), AlQudah (2007) (8), Ibrahim (2010) (19), Hashim (2012) (18) and Yan and Cardinal (2013) (30) recommended that the university should activate practicing sports recreational activities for international students because of their psychological and social benefits in achieving 
communication and interaction between students.

The recommendation of the Al-Ziyud and Ali study (2015) (12) was that international students should be involved in programs and activities that would develop social interaction.

While the results of Nasr study (2017) indicated that the need to recreation was at the top of the social needs of the students with a percentage of $(49.29 \%)$ and that the sports activities were at the forefront of the recreational programs practiced by the international students with a percentage of $(52.99 \%)$ (25).

Particular emphasis is on recreation as a promising tool for creating socially appropriate environments for this group of students. Therefore, the researchers studied and determined the percentage of the contribution of sports recreational preferences in the social adjustment of the international students in Mansoura University.

The Importance and Need of the Research:
-Preparing a standardized data collection tool to measure sports recreational preferences.

- The importance of international students as a segment with a distinct political, economic and cultural return, as well as a mean of strengthening cooperation relations with other countries in the world.

-The increasing numbers of international students in Egypt leads to search for the best ways to meet their needs in light of the growing problems that they face, what need caring and paying attention to them.

- Explain what sports recreational activities can offer to students from social affinity, psychological satisfaction, acceptance of each other and being away from isolationism and many of the existing social diseases.

\section{The Aim of the Research:}

The research aims to determine the relative contribution of sports recreational preferences in predicting social adjustment among the international students at mansoura university. 
.The Questions of the Research:

-What types of sports recreational activities are preferred by the international students at Mansoura University?

-What are the places of practicing the favorite sports recreational activities of international students at Mansoura University?

- What is the level of sports recreational preferences and social adjustment of the international students at Mansoura University?

-What is the relationship between sports recreational preferences and social adjustment among the international students at Mansoura University?

-What is the significance of differences in sports recreational preferences and social adjustment according to the variables of (gender and nationality) of the international students at Mansoura University?

- What is the degree of relative contribution of sports recreational preferences in predicting with social adjustment among the international students at Mansoura University?

\section{Research Procedures:}

\section{Design:}

The researchers used the descriptive design (associative relations) in its steps and procedures.

Society and Sample of the Research:

The research society is determined by the international students of the different faculties in Mansoura University in the Arab Republic of Egypt for the academic year (2016/2017). The total number of students was (2211), representing (25) countries (appendix A).

The researchers selected the sample of the research by the stratified judgmental method of international students and their number was (384) with percentage of $(17.37 \%)$ from (15) countries in percentage of $(60.00 \%)$, divided into (41) international students for the pilot study with a percentage $(1.85 \%)$. In addition to (343) international students, who are registered in the bachelor's or License's degree, by percentage of $(15.51 \%)$ for the basic research sample, practicing sports recreational activities 
and staying in summer holiday in Mansoura or surrounding areas and have never been in the Arab Republic of Egypt before, table (1).

Table (1)

Description of the Basic Research Sample $(n=343)$

\begin{tabular}{|c|c|c|c|c|c|}
\hline \multicolumn{2}{|c|}{ Research variables } & Number & Percentage & Mean & $\begin{array}{l}\text { Standard } \\
\text { deviation }\end{array}$ \\
\hline \multirow{3}{*}{ Gender } & Male & 230 & $\% 10.40$ & \multirow{3}{*}{1.33} & \multirow{3}{*}{0.47} \\
\hline & Female & 113 & $5.11 \%$ & & \\
\hline & Total & 343 & $15.51 \%$ & & \\
\hline \multirow{3}{*}{ Nationality } & Arab & 182 & $\% 8.23$ & \multirow{3}{*}{1.47} & \multirow{3}{*}{0.49} \\
\hline & $\begin{array}{l}\text { Non- } \\
\text { Arab }\end{array}$ & 161 & $\% 7.28$ & & \\
\hline & Total & 343 & $15.51 \%$ & & \\
\hline
\end{tabular}

From Table (1) it is clear that:

-The percentage of international male students in the sample of research is higher than the percentage of female students.

- The percentage of students of Arab nationalities is higher than the percentage of students of other nationalities.

\section{Data Collection Tools:}

The researchers used the following data collection tools:

Social Adjustment Scale: (prepared by Baker, R. and Siryk, B.) (1989).

The scale aims to measure the social adjustment of foreign students. It consists of (20) statements according to the Fifth Likert Scale (completely agree, agree, not sure, disagree, and totally disagree). The grades are calculated in the order $(5,4,3$, 2 , and 1) to the positive statements and vice versa to negative statements and the higher degree of the student on this scale indicate the high level of social adjustment.

The scale has a high degree of stability. Alpha values ranged from (0.83 to 0.91 ), as well as a high degree of validity. The component statements are closely related to the effects of practicing activities of free time on students. It was also used in the study of Al-Sagheer (2001) (9), on the foreign students in Saudi Arabia. 
The coefficient of validity and stability was calculated once again for the scale, the validity coefficient was (0.44: 0.80$)$ and the stability coefficient was (0.70).

The number of statements of the social adjustment scale was (17) statements, with a minimum of 17 degrees and a maximum of 85 degrees in its final form (Appendix D).

Sport

Recreational

Preferences Scale (prepared by the researchers):

The researchers reviewed some of the scientific references from books and researches related to sports recreational activities. They identified both the independent variables and the aspects of the scale, the scientific references were such as Al-Ghareeb (2001) (6), Al-Hamahmi and Abdul Aziz (2009) (7), Dice and Isil (2010) (15), Abdulaziz and Al-Batrawi (2012), (1) (Julie (2013) (20), Sibel (2014) (29), and Al-Samnoudi and others (2016) (10).

The aspects included (concept, objectives, social influences, psychological effects and health effects).
The number of statements placed under each aspect in the scale were (40) statements, taking into account the accuracy of the selection of the statements by making each statement independent from the other and forming it easily and without complexity, in addition to the coordination between the statements of each aspect and not to be repeated.

The independent variables, aspects and statements of the scale were presented in the initial form (Appendix E) to the experts*, who were (7) experts (Appendix C), to express their opinion of agreement or disagreement and any other suggestions for modification and consolidation. The researchers were satisfied with a percentage of $(70.00 \%)$ and more of the opinions of the experts on the independent variables and the aspects and statements of the scale, in order to make the best use of the study.

The Fifth Likert Scale
has been determined
(completely agree, agree, not
sure, disagree, totally disagree)
for the responses of the
research sample, and degrees


are calculated in this order $(5$, $4,3,2,1$ ).

The coefficient of validity and stability was calculated, the validity coefficient was $(0.42$ : $0.94)$, and the coefficient of stability was (0.70: 0.97).

The number of statements of the sport recreational preferences scale reached (33) statements, with a minimum of (33) degrees and a maximum of (165) degrees in the final form (Appendix F).

The two researchers determined levels to be used to make a decision in the total degree of the aspects or the total score of the scale. Their decisions based on the findings of the reference studies and according to the Fifth Likert Scale, (completely agree, agree, not sure, disagree, totally disagree) and responses of the research sample on the statements of the Social Adjustment Scale and the Sports Recreational Preference Scale.

\section{Table (2)}

The Estimate and Descriptive Level of the Social Adjustment Scale and the Sports Recreation Preferences Scale

\begin{tabular}{|c|c|c|c|}
\hline $\mathbf{N}$ & mean & percentage & $\begin{array}{l}\text { The Estimate and } \\
\text { Descriptive Level }\end{array}$ \\
\hline 1 & 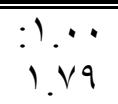 & 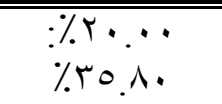 & Very low \\
\hline 2 & $\begin{array}{l}: 1.1 . \\
r .09\end{array}$ & $\begin{array}{l}\% \% 4 . \cdots \\
\% 01 . \wedge .\end{array}$ & Low \\
\hline 3 & d & $\begin{array}{l}\% \text { \%r... } \\
\% \text { \%r.A. }\end{array}$ & Medium \\
\hline 4 & $\begin{array}{l}: r . \varepsilon \\
\varepsilon .19\end{array}$ & $\begin{array}{l}\text { \%ฯィ... } \\
\% \wedge r . \wedge .\end{array}$ & High \\
\hline 5 & $\begin{array}{l}: \varepsilon . Y . \\
0 . .\end{array}$ & $\begin{array}{l}\because \wedge \varepsilon \ldots \\
\% 1 \cdots \ldots\end{array}$ & Very high \\
\hline
\end{tabular}

\section{Basic Study:}

After ensuring validity and stability coefficients, the Social Adjustment Scale and the Sport Recreational

Preferences Scale were applied in the period from $(04 / 08 / 2017)$ to $(25 / 08 / 2017)$. After the application process 
was completed, the data was collected, organized, unloaded and tabulated to perform the appropriate

statistical treatments.

\section{Statistical Methods:}

The researchers used the statistical program SPSS for the following scientific coefficients and statistical treatments: mean, standard deviation, percentage, simple correlation of Pearson, T test of differences and equation of multiple regression analysis.

Interpretation and

\section{Discussion of Results:}

In order to achieve the objective of the research and in response to the questions of the research, within the sample and the methodology used, the researchers present their findings of the results classified as follows:

- Types of sports recreational activities preferred by the international students at Mansoura University (Appendix G).

From Table (3), it is clear that the preferences of international students at Mansoura University for sports recreational activities were (running, walking, biking, pentagonal football, table tennis) respectively.

This may be due to the desire of foreign students to engage in sports recreational activities in free time to create a state of balance between the mental and physical aspects after long periods of study. There are also the sports possibilities necessary for practicing recreational activities throughout the study period. They are easy to practice individually or collectively with colleagues and friends. In addition to the availability of safety factors, especially on campus, as well as the low cost of the tools of practice in most of these sports activities as many foreign students own bicycles to use them to move between housing and the University due to overcrowding in Mansoura city. This is in line with the results of Milanovic and et al. (2013), (21) which indicated that university students are very interested in running sport, and this differs with the results of the study of Mohamed and Hazem (2014) (22) which showed that football activity was at the forefront of the order of 
recreational sports activities preferred by foreign students. While sports recreational activities (wrestling, kickboxing, judo, speedball, boxing) respectively, are less preferred.

This may be due to the weakness of the tendencies and interests of international students in practicing violent sports recreational activities. In addition, most of these sports need tools and sportswear with high cost and special skills to exercise, as well as the lack of popularity of those sports activities in their countries. Moreover, these sports require specialized trainers in private places with availability of safety factors.

- Places of practicing preferred recreational sports for international students at Mansoura University, (Appendix H).

From Table (4), it is clear that international students at Mansoura University prefer practicing recreational sports activities in the Olympic Village of the University and then the Open Pentathlon playground respectively.

This may be due to the satisfaction of international students to the possibilities available in the Olympic Village of the university to practice sports recreational activities, as they are on campus. It has varied places for practicing (football stadium, track for running and walking, pentagon football playgrounds, multipurpose playgrounds, tennis playgrounds, table tennis halls, squash complex, boxing circuit, speedball machines) with many toilets and showers. In addition to the presence of cadres specialized in lighting and technical aspects, management of sports recreational activities establishments, organizing sports competitions and overcoming the obstacles and difficulties that may face foreign students before and during the implementation of sports activities. In addition, the availability of safety factors, the variety of means of advertising, matching finance contributories with most students finance abilities, the existence of boxes of complaints and presenting views by students for the managers of the establishments and sports activities. 


\section{8}

While preferring practicing sport recreational activities is lower in the sports club then in the gymnasium, respectively.

This may be due to the non-admission of international students as members of the sports clubs available in the environment surrounding Mansoura University. Their participation as seasonal members requires very high costs. The sports clubs are limited to specific games and sports that participate in the local competitions and tournaments for Egyptian students only, what causes difficulty in practicing sports recreational activities in those sports clubs to foreign students. - The level of sports recreational preferences and social adjustment among the international students at Mansoura University, (Appendix I).

Table (5) showed that the level of response of international students at Mansoura University on Sports Recreational Preferences Scale was (high), with a (very high) preference level in the aspect of (health effects of sport recreational preferences).
This may be because many international students have the information and knowledge that enable them to understand the concept of recreational activities in their free time. In addition, they understand the activities role in building the individual and the progress of the society by selecting individual and collective sporting activities that positively reflect their wishes and interests during the university day or on holidays to satisfy the social, psychological and health aspects.

In addition, the exercise of preferred sports recreational activities significantly affect the health and physical aspects of the student, through the restoration of activity and vitality after the university day, prevention of the incidence of many diseases and maintain the physical form is consistent and ideal, which gives international students a healthy lifestyle in the new environment. This is in line with the results of the study of Mohamed, Hazem (2014) (22) about the awareness of international students about the objectives of recreational activities. Besides 
the results of the study of AlZiyud and Al-Ali (2014) (12), that the health aspect is one of the most influential areas with sports activities. Moreover, this is consistent with what AlHamahmi and Abdul Aziz (2009) mentioned about the presence of a range of physiological effects of recreational activities (7: 37). While the results of the Qianya and Craig (2014) (27) study differ in that Asian students receive physical gains while participating in recreational sports activities.

The level of response of international students at Mansoura University on Social Adjustment Scale is high. This may be because the international students spent a period in the Egyptian society, providing them with knowledge of the society and gaining experience in how to interact with its members, and recognizing on the prevailing customs and traditions in it. In addition, the ease of acquiring friends and forming relations with others, the comfort of housing and mobility and the existence of a motivation to adjust gradually with the nature of the new society, formed a positive image and thus social adjustment has risen. This is in line with the results of the study of Abu Lail (2010) (3), Azizah et al (2014) (4) and Muslim (2015) (23) that the level of social adjustment of foreign students is high. While the results of Chirs, Edwin, Alfredo (2014) (14) differs in that the level of social adjustment for students from non-European countries was less.

- The nature of the relationship between sports recreational preferences and social adjustment among the international students at Mansoura University (Appendix J).

Table (6) showed that there is a statistically significant positive correlation between the total score of the sports recreational preferences and the social adjustment of the international students. The calculated value of (r) is greater than the tabular value at a significant level (0.05).

This may be because the practice of preferred recreational sports provide students with opportunities for integration and dealing with others of different nationalities 
informally. What leads to formation of different relationships and friendships, the investment of free time in a positive way and eliminate the anxiety and tension that may face the foreign student in his spare time. The preferred sports recreational activities are a wonderful mean to get rid of the problems and pressures of life, because they provide an enjoyable atmosphere, opportunities for social acquaintance and affinity and accept the standards and values of society, which helps in the growth of foreign student's personality and the formation of attitudes and desires. Therefore, the higher the range of practice in sports recreational activities, the higher the level of social adjustment among international students.

This is consistent with the results of the studies by Chris, Edwin and Alfredo (2014) (14), Abdulghani and Arif (2014) (2) and Noraseela, Aminuddin and Shah (2016) (26). That Sports recreational activities have contributed to the formation of friendships and adjustment between students and dealing with others from different cultures and thus integration with the social and academic life of international students.

- Significance of differences in sports recreational preferences and social adjustment according to the variables (gender and nationality) of the international students at Mansoura University (Appendix K).

(Table 7) showed that there are statistically significant differences in sports recreational preferences between males and females in favor of males. The calculated value of $(t)$ is greater than the tabular value at a significant level of (0.05). There are also significant differences in The social adjustment between males and females is in favor of males, since the calculated value of $(t)$ is greater than the tabular value at a significant level of (0.05).

This may be due to the awareness of male students of sportive culture of recreational activities that help them to choose the preferred sport activity and exercise it easily and with others and at different times of the day individually or collectively without adhering 
to the customs, traditions and values related to females in Eastern Egypt. These recreational practices lead to greater involvement in society that causes lower sense of loneliness and social isolation with a high level of social adjustment among foreign male students. This is consistent with the results of the Qianya and Craig study (2014) (27) that there are significant differences in the types of recreational sports on campus between the two genders of Asian international students. This contrasts with the results of the study of Al-Ziyud and Ali (2014) (12) which indicated that females are more affected than males in practicing sports activities, especially on social status.

Table (8) showed that there are statistically significant differences in sports recreational preferences between Arab and non-Arab nationalities in favor of Arab nationalities. The calculated value of $\mathrm{T}$ is greater than the tabular value at a significant level of (0.05). There are also statistical significant differences of the social adjustment between Arab and
non-Arab nationalities in favor of Arab nationalities, where the calculated value of $(t)$ is greater than its tabular value at a significant level (0.05).

This may be because the students from Arab nationalities speak in Arabic, the language of the Egyptian society. These differences because of the knowledge and familiarity of the language of the people from the host country with ease in dealing with them, creating a clear idea of their cultural and civilizational concepts. This helps in the regular practice of recreational sports activities and the active participation in competitions and games carried out by the Department of Expatriates in the campus, which reduces the psychological alienation and reaching a good social level.

- The degree of proportional contribution of sports recreational preferences in the prediction of social adjustment among the international students at Mansoura University (Appendix L).

Of Table (9): it is clear that the interpretation factor $\left(\mathrm{R}^{2}\right)$ of $(26.00 \%)$ refers to the percentage of variance in the 
dependent variable (social adjustment) interpreted by the variance of the independent variable (sports recreational preferences).

This may be because sports recreational preferences explain $(26.00 \%)$ of the variation in the level of social adjustment of the international students, while the remaining variance is due to other variables not taken into account in the regression equation. The higher the range of practicing in sports recreational activities the higher the level of social adjustment among the foreign students.

From Table (10), it is clear that there are statistically significant differences between the sports recreational preferences and the social adjustment of the international students. The calculated value (f) is greater than the tabular value at a significant level (0.05).

This may be because sports recreational preferences have a statistically significant effect on determining the value of the level of social adjustment of foreign students. This is in line with the results of the Jassim, Jabali and Korakis (2012) (16) study that sports activities have a positive impact on social adjustment.

Table (11) shows that there are statistically significant differences between the sports recreational preferences and the social adjustment of the international students. The calculated values of (t) are greater than its tabular value at a significant level of (0.05) and the values of the regression coefficient are positive.

This may be due to the importance of sports recreational preferences in predicting with the social adjustment of international students. The multiple regression coefficient refers to the relationship between sports recreational preferences and social adjustment, that is consistent with the results of the study of Noraseela, Aminuddin and Shah (2016) (26) as the practice of sports activities provide the opportunity to make new friendships and to mix between international students and students of different cultures.

The multiple regression equation that is used to predict 
the social adjustment of international students can be formulated as follows:

Social adjustment $=(29.895+$ 0.235) sports recreational preferences

This may be due to the correlation between sports recreational preferences and social adjustment among international students. A statistically significant positive correlation between sports recreational preferences and social adjustment, it was possible to predict by one of them using the other.

\section{Conclusions:}

Based on the results of the research, and in light of the methodology used, and within the sample, data collection tools and statistical methods used, the researchers provide the following conclusions:

- International students prefer to practice recreational activities: running, walking, cycling and pentagon football in free time.

- The establishments of the Olympic Village at Mansoura University are suitable for the sports recreational activities of the international students.

- The high level of sports recreational preferences and the level of social adjustment of international students.

- The practice of sports recreational activities helps to improve the level of social adjustment among foreign students coming to Mansoura University.

- Male students of Arab nationalities practicing preferred sports recreational activities feel higher social adjustment than female and non-Arab students.

- Preferred sports recreational activities contribute significantly to the level of social adjustment of international students.

\section{Recommendations:}

In the light of the research objective and questions, the methodology used and within the sample, the researchers provide recommendations as follows:

- Using data collection tools to measure the level of sports recreational preferences and the level of social adjustment among international students coming to Egyptian universities.

- Diversity in the establishment of competitions for games and individual sports and conflicts. 
- Conducting cooperation protocols between the university's expatriate administration and the sports clubs in the surrounding community to serve international students.

- Encouraging and motivating students from nonArab countries to practice sports recreational activities through:

- Developing a plan for sports activities through sharing between students and the Department of Sports Activities at the university.

- Preparation of means of advertising about sports activities.

- Coordination between the periods of practice with the different university faculties.

- Providing places of practice with a privacy nature.

- Providing specialized supervisors with proficiency in foreign languages.

- Implementation of sports activities to involve different nationalities.

- Monitoring and evaluation of sports activities provided to students.

- Preparing of an integrated academic, social and psychological guidance program under the supervision of qualified specialists in social counseling on campus.

- Conducting scientific research related to recreational activities in general with the social and psychological variables of the foreign students.

\section{Scientific Sources:}

1- Abdel Aziz, $M$ and Batrawi, A: Introduction to Recreation and Free Time, Mahe for publication and distribution, Alexandria, 2013.

2- Abdulghani A and Arif A: Academic and Social Adjustments of Arab Fulbright Students in American Universities: A Case Study, International Journal of Humanities and Social Science, Vol. 4 No. 5-th March 2014.

3- Abu Lail, A: The Level of Social Adjustment and Academic Adjustment of Arab and Jewish Students at Haifa University (Comparative Study), Master Thesis, Faculty of Education, Yarmouk University, Jordan, 2010.

4- Azizah $\mathbf{R}$ et al: Academic and Social Adjustment of International Undergraduates: A Quantitative Approach, Journal of Economics, 
Business and Management, Vol. 2, No. 4, November 2014.

\section{5- Al-Dabboubi, Aand}

Badawi, A: The Level of Psychological and Academic Adjustment of the Foreign Students in the University of Applied Sciences, Jordanian Journal of Human Sciences, "The Human Sciences Series", Vol. 16, No. 2, 2014.

6- Al-Ghareeb, A: The Recreational Preference of Older Persons in Saudi Society, Journal of Gulf and Arabian Island Studies, vol. 13, No. 1, Kuwait, 2001.

\section{7- Alhamahmi, $M$ and Abdul}

Aziz, A: Recreation between theory and practice, edition 6 , the Book Center for Publishing, Cairo, 2009.

8- Al-Qodah, M: The Degree of Adjustment of Omani Students in the Cultural Environment in Jordanian Universities and Their Relation to Achievement and Some Variables, Journal of Educational and Psychological Sciences, Vol. 8, No. 2, 2007.

9- Al-Sagheer, S: The Social Adjustment of Foreign Students "Analytical Study Applied to Foreign Students at King Saud University in Riyadh, Um Al-Qari
University Journal of Educational, Social and Human Sciences, Vol. 13, No. 1, 2001.

10- Al-Samnoudi et al.: Entrance of the Recreation Sports, Al-Eyman Library, Mansoura, 2016.

11- Al-Zoghbi, A: Comparison of the Sense of Psychological Isolation Among the Students of Sana'a University, Expatriates and NonExpatriates, Journal of the Union of Arab Universities for Education and Psychology, Vol. 1, No. 6, Faculty of Education, Damascus University, Syria, 2013.

12- Al-Ziyud, Kh and Al-Ali, M: The Effect of Sports Activities on Some Variables for Arab Students Coming to Study in the Faculty of Physical Education, Yarmouk University, Al-Najah University Journal of Human Sciences. Vol. 29, No. 5, 2015.

13- Baker $R$ and Siryk B: Student Adaptation to College Questionnaire Manual, Western Psychological Services, Los Angeles, 1989.

14- Chris R, Edwin G, Alfredo U: Recreation, Intercultural Friendship, and International Students' Adaptation to College By 
Region of Origin, International Journal of Intercultural Relations ,Volume 42, September 2014, PP 104-117.

15- Dice $O$ and Isil C: Changes in Leisure and Recreational Preferences: A case study of Ankara, Scientific Research and Essays, Vol. 5, No. 8, 2010. PP 721729.

\section{6- Jassim, D, Jabali, $H$ and} Korakis, Sh: Comparison of Social Adjustment between Female Students Who Practice and not Practice Sports in Girls College of Education, Journal of the College of Basic Education, No. 8, Babel University, Iraq, 2012.

17- Giovanni B and Stefano P: The Effects of Physical Activity on Social Interactions: The Case of Trust and Trustworthiness, Journal of Sports Economics, July 5, 2017.

18- Hashim H.: Perceived Barriers to Recreation Sport Participation in University Students: A Comparison between International and Local Students in the United States, Pertanika, Journal of Social Sciences \& Humanities, University Putra, Malaysia, 20 (1), 2012.
19- Ibrahim, H: The Recreational Activities That the Students of the University of Jordan Tend to Have During the Weekend and Summer Vacations, Journal of Humanities and Social Sciences, Volume 26, No. 4, Deanship of Scientific Research and Graduate Studies, Yarmouk University, Jordan, 2010.

20- Julie J; Leisure and Recreation Preferences of Adolescents with Intellectual and Developmental Disabilities, PH.D, The Department of Health and Human Services, University of Rochester, Rochester, New York, USA, 2013. PP 1- 227.

21- Milanovic $Z$ et al.: Attitudes towards exercise and the physical exercise habits of University of Zagreb students, Annales Kinesiologiae, Vol. 4, No 1, 2013.

\section{2- Mohamed M and Hazem}

M: Recreational Interests of Foreign Students at Mansoura University, The Assiut journal of sport science and arts (AJSSA), Faculty of physical Education, Assiut University, Jan, 2014.

23- Muslim, W: Social and Academic Adjustment of Non- 
Saudi Female Students at King Saud University in Riyadh (Field Study), Master Thesis, College of Arts, King Saud University, 2015.

24- Mustafa, $M$ and AlSherifin, A: The Sense of Psychological Isolation and Psychological Security and The Relationship Between Them in a Sample of Foreign Students at Yarmouk University, Jordanian Journal of Educational Sciences, Vol. 9, No. 2, Deanship of Scientific Research, Yarmouk University, Jordan, 2013.

25- Nasr, O: Contributions of the Method of Working with Groups in Satisfying the Psychological and Social Needs of the Foreign Students, Master Thesis, Faculty of Social Work, Assiut University, 2017.

29- Noraseela M, Aminuddin Y, and Shah P.: Sport activity and cultural integration of international students in University Putra Malaysia, International Journal of Academic Research, Vol.3, Issue 2(5), 2016.
30- Qianya G and Craig M: An Exploratory Study of Asian International Students' Campus Recreational Sports Participation, Recreational Sports Journal, Vol. 38, Issue 1, USA, 2014.

//us.sagepub.com/enus/nam/recreational-sportsjournal/

31- Seyed H: Evaluation and Comparison of Individual and Group Sports in the Social Adjustment of Students, International Journal of Academic Research in Business and Social Sciences, Vol. 2, No. 1, 2012.

32- Sibel A: Factor affecting recreation preferences and expectations of disabled adult learners, Educational research and reviews, Vol. 9, No. 20, 2014. PP 975- 980.

\section{3- Yan $Z$ and Cardinal B:} Increasing Asian International College Students' Physical Activity Behavior: A Review of the Youth Physical Activity Promotion Model, The Health Educator, Journal of Eta Sigma Gamma, Vol. 45, No 1, 2013. https://files.eric.ed.gov/fulltext/ EJ1014997.pdf -21/10/201710:30 AM 